\title{
Effects of Organizational Learning on Project Performance of Construction Firms in Rwanda, a Case of Hygebat Ltd
}

\author{
Batamuliza Mable Kagarama
}

Master of Business Administration (Project Management) Of University Of Kigali

\begin{abstract}
Organizational learning is an important function for enhancing project performance because it enables firm's personnel to acquire and utilize skills and competences through knowledge acquisition, knowledge transformation and knowledge exploitation. This study sought to examine the effects of organizational learning on the project performance in construction firms in Rwanda using the case of Hygebat Ltd. The objectives of the study were to identify the effects of knowledge acquisition analysis, knowledge transformation and knowledge exploitation on the performance of Hygebat Ltd's construction projects. The researcher used a correlation research design to measure the significance of the relationship between organizational learning and project performance. Data was collected from 54 respondents (5project managers and 49 project staffs) using the close-ended questionnaire and personal interview guide. Respondents were selected by use of stratified and simple random sampling techniques. The validity of research instruments was determined using the content validity index while reliability was verified through the pilot-testing method. Data was analyzed through descriptive (frequency and percentage distribution tables) and inferential statistics (multiple linear regression analysis) and qualitative (use of content analysis). Findings show that all the predictor variables under organizational learning have positive but not statically significant effect on the performance of construction projects in Hygebat Ltd. This is confirmed by the regression coefficients which show that $\beta 1=.130(13 \%)$, $\beta 2=.072(7.2 \%)$ and $\beta 3=.042(4.2 \%)$ of the positive performance outcomes of Hygebat Ltd's construction projects are explained by KA, KT and KE respectively. However, the probability values (sig.) of $\mathrm{p}=.244>0.05$ for $\mathrm{KA}, \mathrm{p}=.401>0.05$ for $\mathrm{KT}$ and $\mathrm{p}=.682>0.05$ for KE show that the effect that organizational learning has on project performance is not statistically significant. Therefore, the research accepts all the null hypotheses ( $\mathrm{H} 01, \mathrm{H} 02$ and $\mathrm{H} 03$ ) in explaining the relationship between organizational learning and performance of construction projects in Hygebat Ltd. It is hoped that the study will enable engineers to improve learning and capacity development so that they improve their skills competences and project performance. Other academicians will find the study valuable in benchmarking their studies on the same subject.
\end{abstract}

\section{Introduction}

The increasing globalization and competition among firms has made organizations greatly hit by competition from multinational corporations. This experience has not only been registered in the least developed and emerging economies but also among firms in advanced nations in North America, Europe Asia, and Australia/Oceania. To survive this competition, organizations have facilitated and fostered knowledge discussion among their staffs and across their processes and systems to become innovative, competitive and grow.

In African countries including South Africa, Egypt, Nigeria, Kenya, and Morocco, one of the functions that can be developed to foster knowledge acquisition, transformation, and exploitation for organizational performance and growth is organizational learning. This concept (organizational learning) has long been considered fundamental to the adaptability of behavior and development of knowledge about the world. It is also widely assumed that learning first emerged as animal behavior evolved greater complexity and may have provided new avenues for this complexity to increase (Ginsburg \& Jablonka, 2010; Brown, 2013). The 
general fitness advantage of learning in living organisms including humans seems clear: learning enables an organism to adapt their behavior during without requiring genetic changes across generations.

Among humans, learning leads to the acquisition, assimilation, transformation, and exploitation of knowledge to create value and satisfy human wants. Wallace (2018) argues that in organizational settings, learning takes place at different levels on analysis within the management literature. Firstly, it can occur at an individual level where an employee engages in learning as an individual. Secondly, it occurs at group/team level where a specific unit of an organization such as a department or project decides to engage in learning to improve knowledge diffusion in their department. Thirdly, it is also witnessed at organizational level where the entire organization prioritizes and invests in learning across all functions. Lastly, it can also occur at system level which involves the processes through which information flows and is diffused across the organization.

At whatever dimension it takes place, organizational learning with its effects including knowledge diffusion, innovation, growth, has been identified as one of the most critical functions that improve organizational performance. Drucker and Ferdinand (2013) indicated that knowledge acquisition through organizational learning would replace equipment, capital, materials, and labor, to become the key element in production, service delivery and firm productivity. The authors maintained that competitive advantage and firm performance in the future will be determined by knowledge resources available to the organization through continuous learning.

Today, rapid changes in business environment among African countries have shortened the cycle of core competitiveness and there is essentially no longer any long-term competitiveness (Skerlavaj, et al., 2017). Firms increasingly depend upon knowledge and information to promote innovation and improve their performance (Morgan \& Berthon, 2018). Therefore, businesses and especially construction firms should maintain their competitive advantage by improving and intensifying organizational learning at all levels in all core business functions.

Organizational learning is not simply a sum of individual learning but a renewal process of changing behaviors to enable a firm to achieve both change and growth simultaneously (Murray \& Chapman, 2017) and a process that allows for the testing and challenging of the decision assumption that drive decision models. For example, through learning, organizations develop rich cultures overtime that are in turn deeply embedded in their learning systems (Murray \& Chapman, 2017). The authors argue that these cultures influence the trajectory of firm performance in the long run thus changing the firms' outcomes in terms of revenues, customer satisfaction and shareholder value.

This has been backed by empirical literature for example, in more recent times, several researchers such as Bessant and Caffyn (Murray \& Chapman, 2017) have conducted empirical research designed to establish the relationship between organizational learning and firm performance. Most of this research has been conducted in UK firms where sets of behavioral capabilities have been assigned to developmental levels of continuous learning and improvement. The research contends that higher levels of continuous learning and improvement translates into superior behavioral routines and labor performance which in totality drives firm performance compared to the counterpart firms where such practices are absent. This observation is corroborated by John (2019) whose study of firms in the construction industry in Pakistan where employees who were subjected to routine training in line with their work specialization improves their skills and productivity by more than seventy percent compared to those who never had training. Similarly, Adamson (2017) also revealed similar findings in his study of 56 manufacturing firms in Romania. Brown (2013) and Kariuki (2016) also conducted similar studies in South African and Kenyan firms respectively.

In Rwanda, the construction sector faces huge performance challenges. RDB (n.d.) shows that lack of access to vital information and limited innovative skills severely affect the growth of this sector. In response, the Government of Rwanda has increased government investment in infrastructure expansion and modernization while encouraging firms to bid for the construction projects going on across the country. For example, RDB (2016) shows that in 2014/2015, the construction industry grew at $10 \%$ with expenditure of USD 546 million. In the same period, real estate grew at $7 \%$ with the expenditure of USD 471 million. Data (RDB, 
2016) further indicates that in 2013/2014, construction industry grew at $9.4 \%$ and contributed more than $7 \%$ to the Gross Domestic product. This shows that there is potential for firms in the construction sector to improve their performance.

However, the Rwanda National Construction Industry Policy (Ministry of Infrastructure, 2019) finds that the construction industry in Rwanda faces a severe challenge of lack of capacity development at both institutional and individual level as well as inadequate skills. This is corroborated by the Rwanda Skills Survey (RDB, 2012) which found out that there are over 2,500 unskilled labor technicians and artisans, currently in employment in the industry. Thus, recommending specific in-service training courses to improve skills and competencies of the existing labor force in the construction industry to improve the performance of construction firms.

This study seeks to establish how organizational learning affects performance of construction projects in Rwanda using the case of Hygebat Ltd. This is achieved by assessing the effect of organizational learning on performance (Spicer, 2014) of construction project within organizational component in Rwanda. The research seeks to explore the nature and process of organizational learning evidenced by construction project teams, and to look at the relationships between organizational learning and performance of construction projects in Hygebat Ltd.

Organizational learning is assessed based on Zahra and George (2012) and Lane, et al. (2016) leaning model which divides organizational learning into four phases. These include i) knowledge acquisition, ii) knowledge assimilation, iii) knowledge transformation and iv) knowledge exploitation and how each of these processes affect the financial and non-financial performance goals of construction projects. The study will also identify ways in which organizational learning process can be improved to improve firm innovation and service delivery among construction firms.

Société d'Hydraulique, Génie Civil et Bâtiment (HYGEBAT) was established in 1995 to operate in the construction industry. Since then, the company has gained very solid experience in this field and has won the confidence of many owners and or potential developers. With headquarters in Kigali, Rwanda, the company is involved in construction projects for building, civil engineering, and hydraulics.

Knowledge is a critical source for various organizations in recent years within competitive context of business. Organizational learning as a strategic tool has been proposed in the field of modern business management for gaining competitive advantage and stabilizing organizational performance and success (Saadat \& Saadat, 2016). The aim of organizational learning is not only enhancing employees' knowledge and skills but also developing and growth of the organization and building flexible dynamic systems for attaining a learning organization.

Firms with operations in the construction sector in Rwanda have been, over the years, performing poorly in terms of skills and organizational capacity compared to other businesses. In reiterating the problem of skills and capacity gaps, RDB (2012) shows that the construction sector in Rwanda had a total skills gap of 3,259 labor accounting for $65 \%$ labour force shortage in the construction industry.

It is observed that there is low level of organizational learning among construction firms/projects in Rwanda. For example, RDB (2012) found that the skills gap among technicians was dominated by construction supervisors (40\%), electronics engineering, technicians (18\%), and civil engineering technicians (17\%) which were attributed to low level of organizational learning. The existing employees also need training in soft skills like leadership, business communication, and innovation.

At the organizational level, Hygebat Ltd, one of the construction firms operating in Remera sector also lacks adequate organizational capacity to deliver high quality project deliverables. This is due to shortage of construction expertise, inadequate and poor-quality machinery, and poor organizational learning systems. Therefore, the development and supply of needed skills and capacity development for the construction industry today and in future in Rwanda is experiencing many challenges. This has negatively affected the performance of those firms both financially and on customer satisfaction metrics. 
The researcher believes that continuous organizational learning can provide a sustainable solution for this challenge by providing opportunities to the unskilled workforce with lifelong learning programs in their workplaces in form of apprenticeships. This will enable them to acquire assimilate, transform, and exploit the knowledge and skills gained to improve the performance of construction projects. It is on this basis that this research was undertaken to establish the effects of organizational learning on project performance of construction firms in Remera Sector, using the case of Hygebat Ltd.

\section{LITERATURE}

\section{The Dimensionality Theory of Organizational Learning}

The dimensionality theory/model of organizational learning was developed by Marsick and Watkins (Song, et al., 2016) who argued that organizational learning takes place in seven dimensions (see Table 2.1). They argued that the 7 dimensions characterize all companies that are striving to become learning organizations.

The 7 dimensions include: 1) creating continuous learning opportunities, 2) promoting inquiry and dialogue, 3) encouraging collaboration and team learning, 4) establishing systems to capture and share learning, 5) empowering people toward a collective vision, 6) connecting the organization to its environment, and 7) providing strategic leadership for learning.

\section{The Seven Dimensions of the Learning Organization}

\begin{tabular}{|l|l|}
\hline \multicolumn{1}{|c|}{ Dimension } & \multicolumn{1}{c|}{ Description } \\
\hline Continuous learning & $\begin{array}{l}\text { Opportunities for ongoing education and growth are provided; learning } \\
\text { is designed into work so that people can learn on the job. }\end{array}$ \\
\hline Inquiry and dialogue & $\begin{array}{l}\text { The organizational culture supports questioning, feedback, and } \\
\text { experimentation; people gain productive reasoning skills to express their } \\
\text { views and the capacity to listen and inquire into the views of others. }\end{array}$ \\
\hline Team learning & $\begin{array}{l}\text { Work is designed to use teams to access different modes of thinking; } \\
\text { collaboration is valued by the culture and rewarded; teams are expected } \\
\text { to learn by working together. }\end{array}$ \\
\hline Embedded system & $\begin{array}{l}\text { Necessary systems to share learning are created, maintained, and } \\
\text { integrated with work; employees have access to these high- and low- } \\
\text { technology systems. }\end{array}$ \\
\hline Empowerment & $\begin{array}{l}\text { People are involved in setting and implementing a shared vision; } \\
\text { responsibility is distributed so that people are motivated to learn what } \\
\text { they are held accountable to do. }\end{array}$ \\
\hline System connection & $\begin{array}{l}\text { The organization is linked to its communities; people understand the } \\
\text { overall environment and use information to adjust work practices; } \\
\text { people are helped to see the effect of their work on the entire } \\
\text { organization. }\end{array}$ \\
\hline Strategic leadership & $\begin{array}{l}\text { Leadership uses learning strategically for business results; leaders' } \\
\text { model, champion, and support learning. }\end{array}$ \\
\hline
\end{tabular}

However, the dimensionality model of organizational learning did not clearly explain the processes of organizational learning and knowledge diffusion through which firms and individuals accumulate knowledge necessary for productivity, innovation, organizational performance, and growth. It is the weakness of this model that motivated management researchers to give more recognition to the theory of adaptation, knowledge creation and absorptive capacity theories of organizational learning.

\section{Adaptation Theory}

Adaptation is a behavioral aspect of processing new information, experience, and knowledge (Attewell, 2012). The theory of adaptation was formulated by March(2019) who suggested that organizational learning is a result of behavioral changes reflected as changes in policies, programs, goals, and operational routines. Adaptive processes involve both exploration and exploitation where exploration is the search for new opportunities which includes refinement, choice, production, efficiency, selection, implementation, and execution (March, 2019) while exploitation is the maturation of an existing process or technology. 
March (2019) indicated that organizations balance the two to varying degrees at different points in time. Foregoing exploitation to exploration does not allow a company to benefit from their investments in exploration however organizations that do not engage in exploration find themselves outdone by companies with new technologies. This becomes particularly difficult when companies are called upon to abandon what has long been successful (Nonaka \& Takeuchi, 2015).

The balancing of exploration and exploitation becomes a challenge as one hinders the other. Exploration reduces the speed of exploitation while improvement in skills of an existing process or technology makes experimentation less attractive (March, 2019).

\section{Absorptive Capacity Theory of Organizational Learning}

This theory was developed by Cohen and Levinthal (Lane, et al., 2016) who defined absorptive capacity as "the ability of an organization to recognize the value of new knowledge/information, assimilate it, and apply it to commercial ends." According to them, organizational learning involves three stages which include knowledge identification, knowledge assimilation, and knowledge exploitation.

However, this theory was later expanded by Zahra and George (2012) who categorized absorptive capacity/organizational learning in four dimensions/processes. These include: i) knowledge acquisition, ii) knowledge assimilation, iii) knowledge transformation and iv) knowledge exploitation.

According to Zahra and George (2012), the first two processes are categorized as potential adaptive capacity/learning (the ability to acquire and assimilate knowledge) while the last two are categorized as realized adaptive capacity (the ability to transform and exploit knowledge).

\section{The four processes of absorptive capacity}

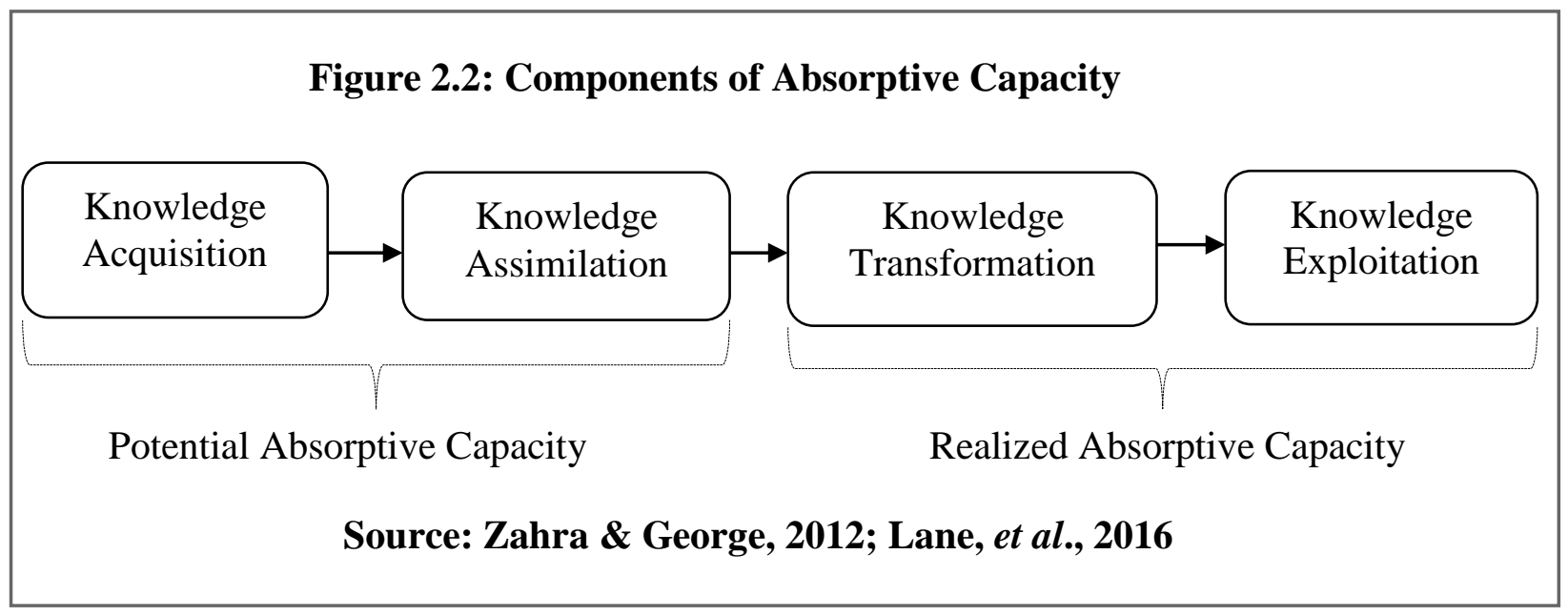

Knowledge acquisition is the ability of an organization to locate, evaluate and acquire outside knowledge and information regarded as essential and relevant for the growth and survival of the organization (Ndiege, et al., 2012). This process is dependent upon prior investment and prior information to influence the outcomes.

Knowledge assimilation which is the second process is the inclusion, conversion, and interpretation of the acquired information (Cohen \& Levinthal, 2013). It represents the capability of the organization to analyze, classify, process, interpret and eventually internalize and comprehend the external knowledge through its own routines in order to understand it better.

Knowledge transformation is the combination of both existing and new knowledge (Zahra \& George, 2012). It refers to the ability of the organization to internalize and convert the newly acquired and assimilated knowledge. It is the capacity of the organization to bring together the existing knowledge with the newly acquired knowledge. The result is a new cognitive composition derived from different sets of knowledge (Ndiege, et al., 2012). 
Knowledge exploitation represents the actual application of knowledge in organizational routines to achieve commercial ends (Lewin, et al., 2011). In simple terms, it is the capacity of the organization to bring together knowledge acquired, assimilated, and transformed for application and use in the operations of the organization to innovate products and services, and improve customer and shareholder value.

\section{EMPIRICAL REVIEW}

Organizational learning has been known to affect performance of firms at both project and department levels (Chen, 2014). However, some empirical research produced mixed results regarding how this function affects financial, human resource and market performance (Becker \& Peters, 2011). The foregoing sections examine the effects of knowledge acquisition, knowledge transformation and knowledge exploitation on the firm/project performance.

\section{Knowledge Acquisition and Project Performance}

Knowledge acquisition has been reported as a fundamental function in promoting innovation, competitiveness, and performance of firms. For example, using survey data from 62 Polish manufacturing companies from the Lubuskie region and from 23 German manufacturing companies from the Brandenburg region, Patalas-Maliszewska and Śliwa (2017) studied the role of knowledge acquisition in company performance. Research results from the German and Polish manufacturing companies surveyed in this study show that the interaction of knowledge acquired from managers, the sales department, and the external research and development units makes a significant contribution to an increase in the success of project realization in a company.

Furthermore, knowledge acquisition has been recognized as a source of enabling lasting competitive advantage in a dynamic and ever-changing competitive business environment (Pacharapha \& Ractham 2012). Holsapple (2015) also argues knowledge to be the only source of sustainable competitive advantage. Mkhize (2015) found that supply chains depend on the ability to acquire knowledge to gain competitive advantage. Similarly, Afolayan, et al. (2016) observed that knowledge acquisition was an important factor that influenced firm innovation, competitiveness and organizational performance among the British companies that were surveyed between 2010 and 2015. This gives credence that knowledge acquisition plays a key role in increasing organizational assets that can be exploited to improve market, financial and human resource performance.

Knowledge is an important source for learning new things, solving problems, creating core competencies, and establishing new positions for individuals and the organization at present and in the future (Nasimi et al., 2013). There are two types of knowledge- explicit knowledge and tacit knowledge (Alwis \& Hartmann, 2018). Explicit knowledge is public and most widely known, and the conventional form of knowledge which can be found in books, journals, and the mass media such as newspapers, television, and internet. In contrast, tacit knowledge is personal and hard to formalize - it is rooted in actions, procedures, commitments, values, and emotions. Tacit knowledge is the less familiar unconventional form of knowledge. It is the knowledge which we are not conscious of. Tacit knowledge is not codified, it is not communicated in a "language", it is acquired by sharing experiences, by observation and imitation (Kikoski \& Kikoski, 2014). A study by Kikoski and Kikosi (2014) found that competitive advantage is gained if companies value their tacit knowledge as explicit knowledge can be known by others as well. Tacit knowledge creates the learning curve for others to follow and provides competitive advantage for future successful companies. Dalkir (2015) identified the properties of tacit knowledge as: ability to adapt, ability to deal with new and exceptional situations; expertise, know-how, know-why and care-why; ability to collaborate, to share a vision, to transmit a culture; and coaching and mentoring to transfer experiential knowledge on a one-to-one, face-to-face basis. All these qualities were found instrumental in promoting organizational competitiveness and performance.

\section{Knowledge Transformation and Project Performance}

It has been observed that knowledge transformation guides firms in formulating effective corporate policies that lead to attainment of organizational vision and employees needs policies that will postulate their employee quality of work life. Curado (2016) suggested that quality of work life can be equated with a set of 
objectives and practices put into action. Organizational policy that considered employee practical participation will satisfy and able to grow and develop as human capital. Policy that accepts employee participation will give employee the opportunity to grow and enjoys their wellbeing, improve employee will have derived quality work life and their engagement to work. Dickson, et al. (2012) studied the effect of corporate policy on firm productivity and found out that firm policies were an important resource for the firm's knowledge management, competitiveness, and performance.

It has been observed that information recording and storage is one of the components of knowledge integration. This function is important in improving knowledge management and firm competitiveness and performance because as knowledge is stored, it enables firms to quickly retrieve it for deployment to counter competition by rival firms thus enabling the firm to stay on top of the competition. A study by Princippe (2012) of manufacturing firms in twelve (12) economies of the European Union: United Kingdom, Belgium, Germany, Italy, Sweden, Finland, Austria, Denmark, France, Hungary, Netherlands, and Greece found out that firms which recorded and safely stored their information and knowledge were more competitive compared to those whose information systems where dormant and underutilized. The firms performed better on indicators such as competition, financial stability, human resources, and market performance. It is therefore worth to note that construction firms among construction firms in Remera sector will likely achieve significant performance if they leverage the importance of knowledge transformation.

Sharing work experiences between staffs which is one of the functions of knowledge transformation in organizational settings has also been identified as a critical practice that promotes innovation, competitiveness, and organizational performance (Zhang \& Jones, 2016). This observation is corroborated by Jantuen (2015) whose study on knowledge-processing capabilities and innovative performance: An empirical study of European firms found that firms where staffs shared their work experiences among themselves registered more outcomes from experiential learning which was easily translated into innovation, knowledge diffusion and organizational performance on almost all performance measures including market, human resource, and financial perspectives.

\section{Knowledge Exploitation and Project Performance}

Knowledge exploitation has been identified as an important function for organization competitiveness, efficiency, and performance because the cost of reusing existing knowledge (exploitation) is lower than creating and recreating knowledge (exploration) because reuse saves time and effort (Watson \& Hewett 2016).

Knowledge-intensive organizations aim at producing knowledge products and service for markets to generate financial value or for corporate social responsibility or for internal use. The outcomes of knowledge exploitation work may include such artifacts as a consultant report for managing organizational change, a scientific article on knowledge management. These are concrete tangible artifacts for use by external and internal customers or interest groups. Blackler (2015) found that knowledge exploitation was an important function for enhancing innovation among firms and projects that had stalled for nearly 10 years. This information and knowledge took the forms of embrained, embodied, encultured, embedded, and encoded knowledge. The outcomes were results of individual and group knowledge processing and learning. These outcomes changed organizational practices were later utilized in future operations and work tasks of the concerned organizations which facilitated improvement in performance.

A study by Ndiege, et al. (2012) on absorptive capacity and its relevancy for large and small enterprises in South Africa observed that knowledge exploitation in small scale firms had immensely helped those firms to improve performance. The benefits of knowledge exploitation in those firms were many including integration of knowledge exploitation for new product development, improved strategies, integration of their information systems, reacting and adapting to market shifts, positioning themselves to better respond to the needs of their customers, creating cohesion between members of the organization, achieving better flow of information and/or communication within and out the organization and taking advantage of external valuable information. Their findings revealed that irrespective of the organization's size, it can benefit significantly from knowledge exploitation. The study further reveals that knowledge exploitation is a strong predictor of an organization's performance and hence a strategic asset for the organization. Organizations 
with high-rate knowledge exploitation are able to apply knowledge within their processes and come up with changes that improve their competitive advantage.

By using the learning-process perspective of absorptive capacity (exploratory, assimilative, transformative, and exploitative learning), Gebauer, et al. (2012) conducted two longitudinal case studies of European electricity providers and suggested that exploitative learning processes, play a key role in strategic innovation and firm performance. This supports the argument that companies should not only manage the accumulation of external knowledge, but also exploit their available capabilities to succeed with strategic innovation. The findings yield a set of research propositions for further academic and managerial consideration.

In a related development, using path analysis in a sample of 461 Greek enterprises participating in the third Community Innovation Survey, Kostopoulos, et al. (2010) demonstrate that knowledge exploitation was directly related to organizational learning and corporate growth and indirectly related to innovation. It was concluded that knowledge exploitation contributes, directly and indirectly, to innovation and financial performance but in different time spans. This study, therefore, contributes to the understanding of knowledge exploitation outcomes by providing empirical evidence of longitudinal form that offers practical implications for organizational performance.

In a related study by Hernaus, et al. (2018) there was empirical evidence of strong, statistically significant, positive relationship between knowledge exploitation and organizational performance. In another words, organizations which developed their capacity and adaptability to exploit knowledge increased their performance far more than those that did not. Furthermore, it showed that employees' measures are the most strongly related with knowledge exploitation and adaptability of an organization, while financial measures were the weakest related. Also, it was established that behavioral and cognitive changes were the organizational learning construct variable which were the most important for enhancing organizational performance in accordance with the fact that information without action does not lead to true learning.

\section{Methodology}

The researcher used a correlation design with both quantitative and quantitative methods. The correlation design was preferred because it helps the researcher to describe the significance of the relationship between organizational learning and project performance in construction projects. According to Amin (2015), a correlation design is the most appropriate research design to be used by the researcher when the study seeks to determine the effect of the independent variables on the dependent variable under investigation.

The target population of this study was 101 people (6 project managers and 95 project staffs) who were selected from Hygebat Ltd in Remera sector Kigali city. Table 3.1 shows the population of the study.

Table 3.1: Target Population

\begin{tabular}{|l|c|}
\hline Population Stratum & Number \\
\hline Project managers & 6 \\
\hline Project staffs & 95 \\
\hline Total & $\mathbf{1 0 1}$ \\
\hline
\end{tabular}

Source: Hygebat Ltd Records, 2021

The 1967 Yamane simplified formula (Israel, 2013) was used in calculating the sample size. This formula is stated as $\mathrm{n}=\frac{\mathrm{N}}{1+\mathrm{N}(\mathrm{e})^{2}}$ where $\mathrm{n}$ is the sample size, $\mathrm{N}$ is the population size and is the level of precision/sampling error ( 0.05 or $5 \%)$. The equation below shows the application of Yamane's formula to the target population.

$\mathrm{n}=\frac{\mathrm{N}}{1+\mathrm{N}(\mathrm{e})^{2}}=\frac{101}{1+101(0.05)^{2}}=\frac{101}{1+101 * 0.0025}=\frac{101}{1.2525}=81$

Therefore, the overall sample size was 81 respondents (project managers and project staffs) of Hygebat Ltd construction projects. 
However, the researcher further calculated the subsample size of each population stratum (project managers and project staffs. This was done using Kothari's (2004) stratified sampling formula as illustrated below:

$N_{i}=n\left(\frac{\mathrm{P}_{i}}{N}\right)$, where.

i. $\quad \mathrm{N}_{\mathrm{i}}=$ Total sample size required from a given population stratum;

ii. $\quad \mathrm{n}=$ Total sample size required from the overall population (81).

iii. $\quad \mathrm{N}=$ Total Population (101);

iv. $\quad \mathrm{P}_{i=}$ Subpopulation of the given stratum;

v. $\quad i=\mathrm{A}$ number that distinguishes one population stratum from others (e.g., $\mathrm{P}_{1}, \mathrm{P}_{2} \ldots$ )

Project managers $\left(\mathrm{N}_{1}\right)=n\left(\frac{\mathrm{P}_{1}}{N}\right)=81\left(\frac{6}{101}\right)=81(0.0594059405)=5$

Project staff $\left(\mathrm{N}_{2}\right)=n\left(\frac{\mathrm{P}_{2}}{N}\right)=81\left(\frac{95}{101}\right)=81(0.9405940594)=76$

Therefore, the total disaggregated sample size from each population stratum was 5 project managers and 76 project staff members selected from Hygebat Ltd construction projects in Remera sector as Table 3.2 shows.

Table 3.2: Sample size and sampling technique

\begin{tabular}{|l|c|c|}
\hline Population Stratum & Number & Sampling technique \\
\hline Project managers & 5 & Stratified and simple random sampling \\
\hline Project staffs & 76 & Stratified and simple random sampling \\
\hline Total & $\mathbf{8 1}$ & \\
\hline
\end{tabular}

The researcher used stratified and simple random sampling techniques in selecting the sample size from each of the population strata. In applying stratified sampling, the researcher disaggregated the population into two categories based on their unique characteristics related to the understanding of the organization. These two strata were made of 6 project managers and 95 project staffs. In applying simple random sampling, the researcher wrote numbers 1-6 on pieces of paper after which the papers were folded and mixed in a box. Each project manager was requested to pick their lucky numbers and 5 project managers who picked numbers 1-5 were considered to participate in the study. The same process was repeated for project staffs where numbers 1-95 were written on pieces of paper, mixed and put in a box. Project staffs were requested to pick their lucky numbers and staffs who picked numbers 1-76 were considered to participate in the study.

The researcher used two instruments/methods during data collection process. These included the questionnaire and interview guide. The questionnaire was designed with response options to ease the data collection process used and it was used for collecting primary data. It was preferred because it collects information from many respondents in a projected time frame. Only close-ended questions were used in the questionnaire because they are considered easy to answer. The interview guide with open-ended questions was used to collect qualitative data. This questionnaire was administered to two project managers and 2 project staffs. They were composed of questions which requested respondents to explain the methods of organizational learning, the importance of each method towards project performance and the challenges faced by Hygebat Ltd in each of the stated methods.

\section{Presentation, Analysis and Interpretation Of Findings}

The first objective was to establish the effects of knowledge acquisition on the project performance of construction firms - Hygebat Ltd.

It is shown that knowledge acquisition has a positive but not statistically significant effect on the performance of Hygebat Ltd's construction projects because it enables project teams to acquire the necessary knowledge required for improved performance. Findings show that through knowledge acquisition, project staffs can learn from their peers, benchmark their projects through field tours, learn from construction experts and mass media insights. 
The regression coefficient of $\beta_{1}=.130$ with $p=.244>0.05$ shows that $13 \%$ of the performance rate of Hygebat Ltd's projects is explained by effective knowledge acquisition $\left(\mathrm{X}_{1}\right)$ function which is not statistically significant.

The second objective was to determine the effects of knowledge transformation on the project performance of construction firms - Hygebat Ltd. Findings also show that knowledge transformation had a positive but not statistically significant effect on performance of construction projects in Hygebat Ltd by enabling staffs to translate new knowledge into actions for achieving organizational goals. The effects include recording the knowledge obtained, knowledge sharing, information synthesis, quality control and self-appraisal. These have facilitated Hygebat project teams design effective project implementation strategies and plans.

The regression coefficient of $\beta_{2}=.072$ with $p=.401>0.05$ at a $5 \%$ level of significance shows that $7.2 \%$ of the performance outcomes of Hygebat Ltd's construction projects is explained by knowledge transformation $\left(\mathrm{X}_{2}\right)$ processes but the outcomes are not statistically significant.

The third objective was to assess the effects of knowledge exploitation on the project performance of construction firms - Hygebat Ltd. Results show that knowledge exploitation has a positive but not statistically significant effect on the performance of Hygebat Ltd's construction projects in terms of enabling project staffs to turn the acquired knowledge into valuable products and services.

The specific effect of this organizational learning process has been identifying as adoption of best practices in construction, responding to customer complaints and needs, ensuring organizational efficiency, promoting innovations, etc. These have facilitated Hygebat Ltd to implement quality projects.

The regression coefficient of $\beta 3=.042$ with $p=.682>0.05$ at a $5 \%$ level of significance shows that $4.2 \%$ of the performance outcomes in Hygebat Ltd can be explained by knowledge exploitation (X3) practices but this effect is not statistically significant.

\section{Conclusion}

The study was conducted on the effects of organizational learning on the project performance of construction firms in Rwanda. The specific objectives were to assess the effect of knowledge acquisition, knowledge transformation and knowledge exploitation on the performance of construction projects in Hygebat Ltd.

The study was based on the null hypotheses $\left(\mathrm{H}_{0}\right)$ which suggested that knowledge acquisition $\left(\mathrm{H}_{0} 1\right)$, knowledge transformation $\left(\mathrm{H}_{0} 2\right)$ and knowledge exploitation $\left(\mathrm{H}_{0} 3\right)$ have no statistically significant effect on the performance of construction projects in Hygebat Ltd.

Based on the findings, it can be concluded that all the predictor variables under organizational learning have positive but not statically significant effect on the performance of construction projects in Hygebat Ltd. Thus this research accepts all the research hypotheses.

This is confirmed by the regression coefficients which show that $\beta_{1}=.130(13 \%), \beta_{2}=.072(7.2 \%)$ and $\beta_{3}=.042$ $(4.2 \%)$ of the positive performance outcomes of Hygebat Ltd's construction projects are explained by KA, $\mathrm{KT}$ and KE respectively.

However, the probability values (sig.) of $\mathrm{p}=.244>0.05$ for KA, $\mathrm{p}=.401>0.05$ for $\mathrm{KT}$ and $\mathrm{p}=.682>0.05$ for KE show that the effect that organizational learning has on project performance is not statistically significant.

The process of organizational learning faces various challenges including inadequate construction experts, limited construction technology, limited funding, growing competition in the construction sector and illiteracy among project staffs among others.

\section{Recommendations}

\section{To Hygebat Ltd Management}

There is need to always recruit workers with relevant literacy rate to ensure that they are able to read and write technical documents used during the construction process. 
It is important to form alliances with other construction experts in Rwanda who will engage with and mentor Hygebat Ltd's staffs who lack adequate engineering skills especially the new recruits

There is need to purchase advanced construction machinery and technology to ensure that the company keeps up to date on the changes in the construction industry

\section{To Hygebat Ltd Staff}

Keep their project information safely and securely to ensure that information on lessons learned from past project remains safe for use in future projects.

There need to regularly attend adult literacy and numeracy training programs so that they become effective in reading writing and mathematics for effective performance of their construction work.

There is need to join the institute of engineers Rwanda for their recognition as credible engineers and to access opportunities for continuous professional development.

\section{To Institute of Engineers Rwanda}

There is need to regularly organize conferences and workshops for sharing knowledge between expert and new members such that every engineer improves on their capacity.

\section{Project Owners}

There is need to always stick to the original construction plans for their houses in order to avoid extra costs that are added after they suggest new changes to the building designs when the structures are already midway under construction.

\section{Suggestions for Further Research}

The study was conducted on a single organization and this may affect the generalizability of findings. More research is needed on the effects of organizational learning on project performance covering at least eighty percent of the construction firms and projects in Rwanda in order to improve reliability and generalizability of findings.

\section{References}

1. Adamson, T. (2017). The study of the causal relationship between organizational learning and performance in the manufacturing sector in Romania, Journal of Manufacturing, 12(4), 341-368

2. Afolayan, A., White, G.R.T., \& Mason-Jones, R. (2016). Why Knowledge Acquisition is Important to effective Supply Chain Management: The Role of Supply Chain Managers as Knowledge Acquisitors. Conference Paper Presented at the British Academy of Management at Newcastle on September $2016 \quad$ [Onlone]. Available at https://www.researchgate.net/publication/307992277_Why_Knowledge_Acquisition_is_Important_t o_effective_Supply_Chain_Management_The_Role_of_Supply_Chain_Managers_as_Knowledge_A cquisitors/link/57d66e4608ae6399a393f9a9/download (Accessed March 10, 2021).

3. Agarwal, R., \& Tanniru, M.R. (2016). Knowledge acquisition using structured interviewing: an empirical investigation. Journal of Management Information Systems, 123-140.

4. Ahmed S., Hoque, I. \& Sobuzi, H.R. (2017). Analysis of Skilled Worker Criteria of Construction Industry. Journal of System and Management Sciences, 7(2), 53-78

5. Alwis, R.S., \& Hartmann, E. (2018). The use of tacit knowledge within innovative companies: Knowledge management in innovative enterprises. Journal of Knowledge Management, 12(1), 133147.

6. Amaratunga, D., Haigh, R., Elvitigala, G., \& Shanmugam, M. (2020). Construction and Women: Promoting Construction Careers for Women in the North West [Online]. Available at: https://hub.salford.ac.uk/uprise-centre-for-disaster-resilience/wp-

content/uploads/sites/163/2020/06/Women-in-Construction-Final-Report.pdf (Accessed August 29, 2021).

7. Amin, E. M. (2015) Social science research: Conception, methodology and analysis. Makerere University Printery 